\title{
Widespread hepatitis $B$ virus genotype $G$ (HBV-G) infection during the early years of the HIV epidemic in the Netherlands among men who have sex with men
}

Marion Cornelissen', Fokla Zorgdrager', Sylvia M. Bruisten², Margreet Bakker', Ben Berkhout ${ }^{1}$ and Antoinette C. van der Kuyl ${ }^{1 *}$

\begin{abstract}
Background: Hepatitis B virus (HBV) variants belong to different genotypes, A-J, whose worldwide distribution is linked with geography, probably because viral spread was associated with ancient human migrations. HBV genotype $\mathrm{G}(\mathrm{HBV}-\mathrm{G})$ is an aberrant genotype with little sequence divergence, suggesting a recent origin. HBV-G is strongly associated with certain risk groups such as intravenous drug users (IDUs) and men who have sex with men (MSM), but hardly with geography. The origin and epidemiology of HBV-G remain unresolved, as is the disease association.

Methods: To estimate the prevalence and possible time of introduction of HBV-G into the MSM community in Amsterdam, the Netherlands, we have retrospectively analysed 226 blood serum samples from HBsAg positive MSM enrolled in the Amsterdam Cohort Studies (ACS) on HIV infection and AIDS dating from 1984 to 1999 using genotype-specific PCR assays.

Results: Of the $226 \mathrm{HBsAg}$-positive samples, 149 were HBV DNA positive. Of those, 104 were positive for HBV genotype A (HBV-A) and five for HBV-G, and 40 showed a dual infection with both HBV-A and HBV-G. Being HIV-infected was significantly associated with a reduced HBV DNA viral load in blood, but not with the prevalence of HBV-G. Early virus already contained stop codons in the precore region and a $36 \mathrm{bp}$ insertion in the core gene which are the characteristics of HBV-G.

Conclusions: HBV-G was introduced before 1985 into the Amsterdam MSM community. Early isolates show very limited sequence variation, confirming a low evolutionary rate. HBV-G acquisition was independent of HIV infection, but being HIV-infected was significantly associated with a reduced HBV viral load in blood, indicating a beneficial effect of early HIV infection in controlling HBV replication.
\end{abstract}

Keywords: Hepatitis B virus, Genotype, MSM, HIV-1

\footnotetext{
* Correspondence: a.c.vanderkuy|@amc.uva.nl

'Laboratory of Experimental Virology, Department of Medical Microbiology,

Center for Infection and Immunity Amsterdam (CINIMA), Academic Medical

Center of the University of Amsterdam, Meibergdreef 15, 1105 AZ

Amsterdam, The Netherlands

Full list of author information is available at the end of the article
} 


\section{Background}

The hepadnavirus hepatitis B virus (HBV), a causative agent of cirrhosis and liver cancer, is currently divided into ten genotypes, named A-J, several subgenotypes and recombinant forms whose dispersal is largely connected with geography [1]. For instance, genotype $\mathrm{A}$ is the most common variant in northern Europe, while genotype D is more prevalent in eastern and southern Europe [1]. Genotype G, an aberrant HBV genotype without a clear geographic association, is also present in certain risk groups in Europe. The prevalence of HBV infection is low in western Europe, e.g. HBsAg prevalence is $<1 \%$ in most northern and western countries, and $<0.5 \%$ in the Netherlands [2]. Higher rates of HBV infection in Europe are apparent for migrants, men who have sex with men (MSM) and intravenous drug users (IDUs). HBV-A2 is the most prevalent HBV genotype in the Netherlands, in particular among MSM [3]. Infections with HBV-G occur in this risk group, but interestingly mainly as co-infections with HBV-A2 and human immunodeficiency virus type 1 (HIV-1) [4]. Worldwide, HBV-G has almost exclusively been found in HIV-infected MSM and IDUs [5-12], suggesting a strong association with those risk groups. Although HBV-G was also detected in two Mexican children, the genotype is not endemic in Mexico and the children were most likely infected either through blood transfusion or close contact with a family member that might belong to a risk group [13]. Mono-infections with HBV-G are uncommon [14-16] as the virus apparently does not replicate well due to a 12 amino acid insertion in the Core protein that interferes with virion secretion and stop codons in the precore region that prohibit $\mathrm{HBeAg}$ expression $[17,18]$.

Rescue by a helper virus restores $\mathrm{HBV}-\mathrm{G}$ production such that it can even outcompete the helper genotype [19-21]. Most HBV-G infections described are thus coinfections with HBV genotype A in France [22], Spain [6], Japan [7, 20], the USA [21, 23] and Canada [9], with HBV genotypes A, C or D in Germany [24, 25], with HBV genotype $\mathrm{A}$ or $\mathrm{H}$ in Mexico [8], and with $\mathrm{HBV}$ genotype $\mathrm{F}$ in Argentina and Brazil [11].

Global HBV-G isolates are closely related and show very little sequence divergence [26], suggestive of a relatively recent evolutionary origin [27], and/or a comparatively recent introduction in the risk groups. It is thus possible that HBV-G was a recent introduction into the Netherlands. Retrospective incidence data and sequence analysis of early virus isolates could thus shed light on the history of this peculiar HBV-G genotype. The Amsterdam Cohort Studies (ACS) on HIV and AIDS started in October 1984 with the inclusion of MSM and IDUs from Amsterdam, the Netherlands [28]. The early blood samples were collected before the era of effective and extensive HBV vaccination and antiviral treatment.
Therefore, we set out to retrospectively determine the prevalence of HBV-G and HBV-A infections in HBsAgpositive participants of the ACS with or without HIV infection that were collected from 1984 to 1999. In addition, a characterization of certain genome characteristics was performed for historical HBV-G isolates.

\section{Methods}

\section{Patient material}

The ACS started enrolling asymptomatic 18-65 year old MSM with at least two sexual partners in the 6 months prior to intake in October 1984. Participants were mainly recruited through the gay press, advertisements and by word of mouth. An undetermined number had taken part in an earlier trial investigating the efficacy of an HBV plasma-derived vaccine that was running from November 1980 till December 1981 [28]. Between April 1985 and February 1988 only HIV-seronegative men could enter the study. From February 1988 until December 1998, admission was re-opened for HIV-infected individuals.

From the ACS, blood samples from MSM were selected that met the following criteria: HBsAg-positive and preferably also HBcAb-positive and sampled before the year 2000 [29]. A total of 226 patient samples were HBsAg-positive, of which 222 also tested HBcAb-positive at the same moment. CD4+ T-cell counts at sampling date were available for 196 participants, both HIV-positive and HIVnegative MSM. All blood samples have been stored at $-80^{\circ}$ $\mathrm{C}$ for the entire period; thaw-freeze cycles were limited to 0-1 during storage.

\section{Real-time PCR assays}

Viral DNA was isolated from serum samples with the QIAamp UltraSens Virus Kit (QIAGEN, the Netherlands). Single-tube real-time PCR reactions that specifically quantify HBV genotype A or G DNA were performed as described [4], for the primer sequences, see also Additional file 1: Table S1. The primers and probes used are highly specific for the targeted HBV genotype (either A or G) and have a lower limit of detection of 5 copies per reaction (=1000 copies $/ \mathrm{ml})$ of the targeted genotype in a background of up to $10^{8}$ copies of the non-targeted genotype [4].

\section{Genotype-specific PCR assays}

Real-time PCR results were confirmed using a genotype A or G specific nested PCR. The first PCR spans the 3'end of the pol gene and part of the X gene (nt 692-1823 from the EcoRI site). The nested PCR amplifies a fragment of 762 base pair (bp) (nt 902-1664 from the EcoRI site), and is able to detect $5-10$ copies of input DNA.

Genotype-specific primers amplifying the precore region were developed for $\mathrm{HBV}-\mathrm{C}, \mathrm{D}, \mathrm{F}$ and $\mathrm{H}$ with the first PCR amplifying a fragment spanning nt. 1728-2071 and a nested PCR amplifying nt 1751-2034. All genotype-specific 
primer sequences are given in Additional file 1: Table S1. The nested PCR's detect 5-10 copies of the specific HBVDNA per reaction. Any amplified products were analysed by sequencing (see below). Non-target genotypes were sometimes amplified when the input DNA of the nontargeted genotype was $\geq 10^{5}$ copies $/ \mathrm{ml}$.

To investigate the presence of stop codons in the precore gene and the $36 \mathrm{bp}$ insertion in the core gene, a fragment of 232 (HBV-A) or 268 (HBV-G) bp, encompassing the precore and core region of the viral genome (see Additional file 1: Table S1 for primer sequences), was amplified with a nested PCR that detects 5-10 copies of HBV-DNA per reaction, from blood serum samples and directly sequenced with the BigDye Terminator cycle sequencing kit (Applied Biosystems, Foster City, CA, USA). Electrophoresis and data collection were performed on an ABI PRISM 3100 genetic analyser (Applied Biosystems, Foster City, CA, USA). Sequences were assembled with CodonCode Aligner [30], and aligned with reference HBV sequences from the NCBI nucleotide database [31] using ClustalW implemented in BioEdit Sequence Alignment Editor version 7.0.9 [32].

\section{$\mathrm{HBeAg}$ analysis}

HBeAg expression in apparently HBV-G mono-infected samples was analysed using the Liaison ${ }^{\circ} \mathrm{HBeAg}$ chemiluminescence immunoassay (DiaSorin SpA, Saluggia, Italy).

\section{Statistical analysis}

Statistical analyses were performed in GraphPad Prism 5 (GraphPad Software, La Jolla, CA).

\section{Results}

Prevalence of HBV-G in MSM in Amsterdam 1984-1999

A total of 226 serum samples from the ACS that were $\mathrm{HBsAg}$-positive and in majority also $\mathrm{HBcAb}$-positive were retrospectively analysed for the presence of HBV-A and/or HBV-G DNA using real-time PCR assays and a confirmatory PCR with genotype-specific primers.

The majority of samples selected were from 1985 to 1986 (170/226 samples, 75 \%) (Fig. 1). A total of 149/ 226 (66 \%) of the samples were HBV DNA positive (Table 1), and of those, 40 samples (27\%) displayed a dual infection with both HBV genotypes A and G, while five sample appeared to be mono-infected with HBV-G. Amplification of other "helper" HBV genotypes from these samples remained negative with both type-specific and more general primers.

In this cross-sectional analysis, HBV DNA prevalence was slightly higher $(73 \%)$ in HIV-negative MSM than in HIV-positive MSM (63\%), but this difference was not statistically significant (Chi-square test $p>0.1$ ). Dual infections with both HBV-A and HBV-G were more prevalent in HIV-positive MSM (33 \% vs. $17 \%$ in HIV-negative MSM) but this difference was again not significant (Chi-square test

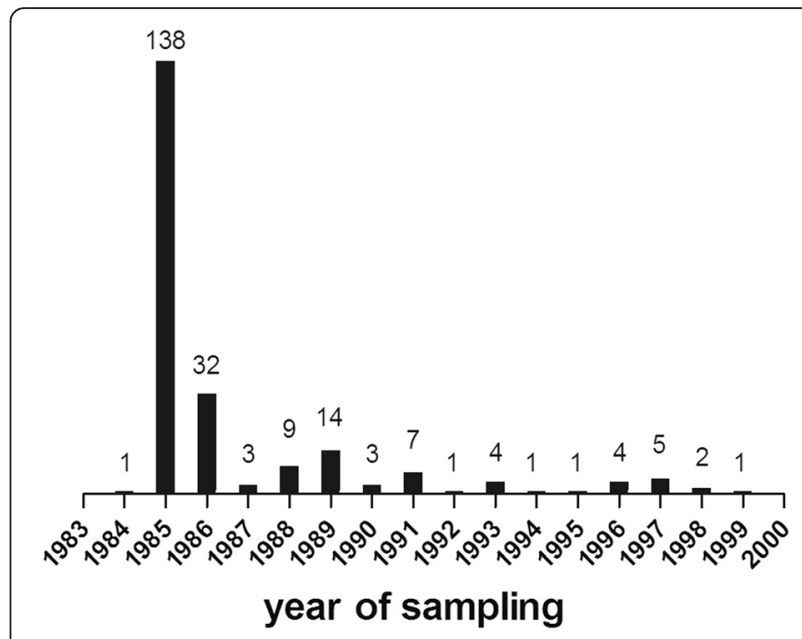

Fig. 1 Number of Dutch MSM samples selected from the ACS with regard to year of sampling. Numbers of blood serum samples selected from the ACS are shown. Samples were selected when they fulfilled the following criteria: originating between 1984 (start of the ACS) and 1999, and having been tested HBsAg and preferably $\mathrm{HBCAb}$ positive

$p>0.05$ ). Mono-infections with HBV-G were equally distributed between the two groups: 2 mono-infections (4 \%) with HBV-G in HIV-negative versus 3 monoinfections (3 \%) in HIV-positive MSM.

Surprisingly, HBV-A and HBV-G DNA was only present in samples from 1985 to 1987 in HIV-negative MSM, but not in subsequent years (Fig. 2a). For HIVpositive MSM, HBV DNA could be detected in samples up to 1997, although the numbers of positive samples decreased over time (Fig. 2b). These findings correlate well with the strongly declining numbers of individuals after 1986 that met our selection criteria involving serological evidence of HBV infection (Fig. 1), and are in line with an earlier report on a profound decline of the HBV incidence in the ACS after the first years of its establishment [29].

Table 1 HBV-A and HBV-G DNA detection in blood serum samples from Dutch MSM 1984-1999

\begin{tabular}{llll}
\hline $\begin{array}{l}\text { HBV genotype } \\
\text { amplified }\end{array}$ & $\begin{array}{l}\text { No. of samples } \\
(100 \%)\end{array}$ & $\begin{array}{l}\text { No. of HIV-positive } \\
\text { samples } \\
N=152\end{array}$ & $\begin{array}{l}\text { No. of HIV-negative } \\
\text { samples } \\
N=74\end{array}$ \\
\hline HBV-A & 104 & 61 & 43 \\
HBV-G & 5 & 3 & 2 \\
HBV-A and -G & 40 & 31 & 9 \\
$\begin{array}{l}\text { Total no. of } \\
\text { samples with } \\
\text { HBV-A and/or } \\
\text { HBV-G DNA }\end{array}$ & $95(63 \%)$ & $54(73 \%)$ \\
\hline
\end{tabular}


a

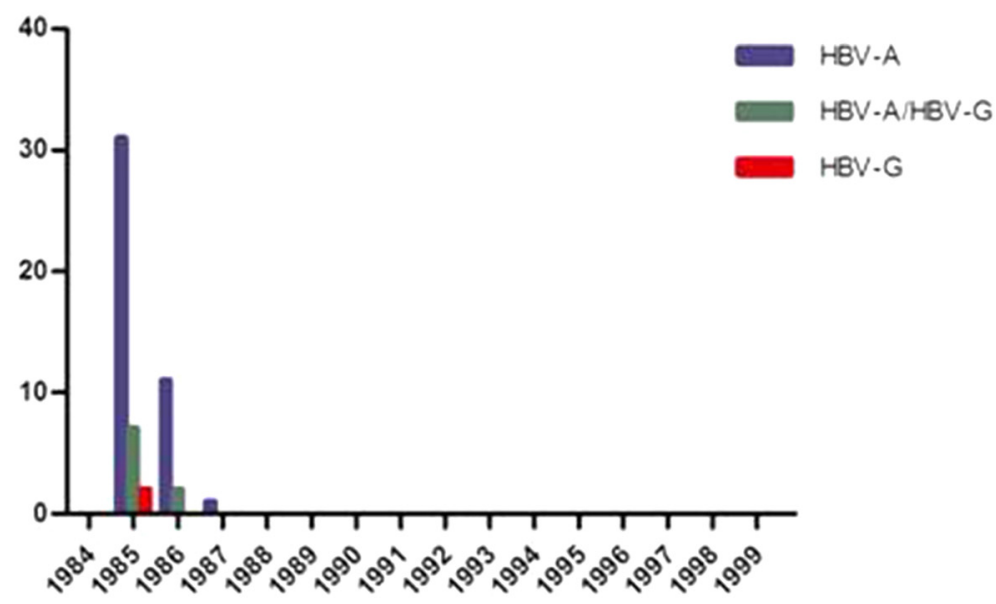

b HIV positive

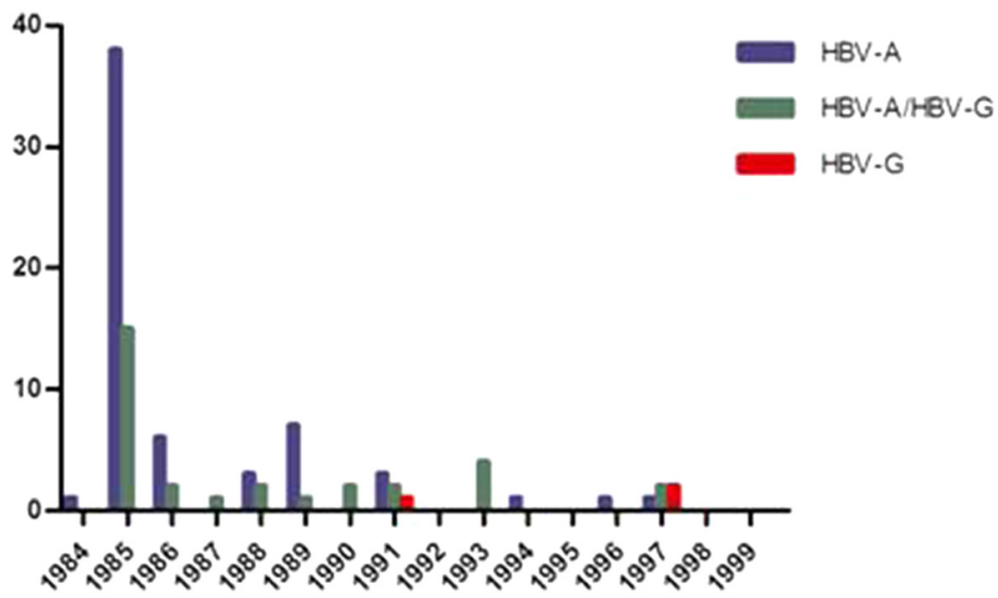

Fig. 2 Numbers of MSM that were HBV-A and/or HBV-G DNA positive with regard to year of sampling and HIV status. The numbers of MSM from the ACS during 1984-1999 that tested either HBV-A, HBV-G or HBV-A and HBV-G positive using two genotype-specific real-time PCR assays followed by a genotype-specific nested PCR to confirm the real-time PCR results. Results are shown in panel (a) for HIV-negative MSM ( $N=74)$ and in panel (b) $(N=95)$ for HIV-positive MSM

\section{Prevalence of HBV-G in MSM in Amsterdam in 1985 with regard to their HIV status}

Because HBV DNA prevalence decreases sharply after 1986 in HIV-negative MSM, the prevalence of HBV DNA in blood was calculated for 1985, the year with the highest number of HBV positive MSM, to compare values between those infected and uninfected with HIV (Fig. 2). In 1985, HBV-G DNA was detected in 9/40 (23\%) of the HBV DNA positive/HIV-negative MSM and in 15/53 (28\%) of the HBV DNA positive/HIV-positive MSM (Fisher's exact test, two-tailed, $p>0.1$, implicating that HBV-G infection was not more common among those infected with HIV than those without HIV infection. Adding data for 1986, the only other year with appreciable HBV DNA positivity for HIVuninfected men, did yield similar prevalence values for
HBV-G infection (21\% in HIV- uninfected versus $28 \%$ in HIV- infected MSM, Fisher's exact test, two-tailed, $p>0.1$ ).

\section{HBV-G mono-infection and HBeAg expression}

HBV-G does not express Hepatitis B "e" antigen (HBeAg), probably due to its non-functional precore region $[14,15$, 17]. So, in any HBV-G positive samples displaying $\mathrm{HBeAg}$ positivity, expression is most likely due to co-infection with another HBV genotype. Therefore, we measured $\mathrm{HBeAg}$ in the five apparent HBV-G mono-infections, and found it to be present in one of these five samples (Table 2). Unfortunately, in the three samples from 1985 to 1991, dual infected samples used as controls were also HBeAg-negative, suggesting that sample age and/or storage conditions could have an effect on the assay, limiting 
Table 2 HBeAg in HBV-G mono-infection

\begin{tabular}{|c|c|c|c|c|c|c|c|}
\hline Patient no. & Year & HIV serology & HBV genotype PCR & HBV-A cps/ml & HBV-G cps/ml & HBeAg (PEI U/mL $\left.{ }^{a}\right)$ & HBeAg result \\
\hline ACS-850676 & 1985 & NEG & G & - & $2.69 E+02$ & $<0.0100$ & NEG \\
\hline ACS-850530 & 1985 & NEG & G & - & $1.67 E+02$ & $<0.0100$ & NEG \\
\hline ACS-916078 & 1991 & POS & G & - & $1.39 E+02$ & $<0.0100$ & NEG \\
\hline ACS-971256 & 1997 & POS & G & - & $3.14 \mathrm{E}+04$ & $<0.0100$ & NEG \\
\hline ACS-970660 & 1997 & POS & G & - & $9.49 \mathrm{E}+09$ & 3.61 & POS \\
\hline ACS-850622 & 1985 & NEG & $\mathrm{A} / \mathrm{G}$ & $5.83 E+05$ & $5.52 E+05$ & $<0.0100$ & NEG \\
\hline ACS-850626 & 1985 & NEG & $A / G$ & $1.44 \mathrm{E}+05$ & $3.85 E+03$ & $<0.0100$ & NEG \\
\hline ACS-916084 & 1991 & POS & $A / G$ & $7.22 E+03$ & $8.01 E+02$ & $<0.0100$ & NEG \\
\hline ACS-972833 & 1997 & POS & $A / G$ & $5.59 E+08$ & $2.36 \mathrm{E}+08$ & 7.57 & POS \\
\hline ACS-972876 & 1997 & POS & $A / G$ & $1.65 E+08$ & $3.34 \mathrm{E}+02$ & 13.5 & POS \\
\hline
\end{tabular}

${ }^{\mathrm{a} P a u l}$ Ehrlich Institute units $/ \mathrm{mL}$

its predictability. Alternatively, samples could be $\mathrm{HBeAg}$ negative due to preceding $\mathrm{HBeAb}$ seroconversion. From the four samples tested from 1997, the dual infected samples and one of the apparently mono-infected samples (no. ACS-970660) exhibited HBeAg positivity, whereas the other mono-infected sample (no. ACS-971256) was negative for $\mathrm{HBeAg}$, suggesting that it could represent a true HBV-G mono-infection. Repeated attempts to amplify a helper HBV genotype from samples ACS-850676, ACS850530, ACS-916078, ACS- 971256 that were HBeAg negative and sample ACS-970660 that was HBeAg-positive, failed. Using other samples from patient ACS-970660 collected 14 days before and 29 days after sample ACS-970660 was obtained also did not result in the amplification of another HBV genotype. Using forward and reverse primers destined for specific genotypes in various combinations also did not result in the amplification of PCR products of the expected lengths for any of the samples.

\section{HBV-G and HBV-A serum viral load in HIV-positive and HIV-negative individuals}

As HBV DNA detection was performed using a real-time PCR assay, the viral load of the samples could be calculated. HBV-A, acting as a helper virus, is known to increase the HBV-G viral load, therefore, the HBV-G viral loads in mono- or dual infected samples should be analysed separately. However, mono-infection with HBV-G is a rare phenomenon, which was also the case in the present study. Therefore, we only analysed the HBV-G viral load in HBV-A and HBV-G double-infected MSM. For HIV-negative MSM, only samples from 1985 to 1986 yielded HBV DNA, therefore the HBV-G viral load comparisons were restricted to that period (Table 3). A $\log _{10}$ lower mean HBV-G viral load was found in HIV-infected MSM, which was statistically significant (Student's $t$-test, two-tailed, $p=0.0063$ ).

The HBV-A viral load was calculated from the real-time PCR data for four groups of patients in 1985 and 1986 ( N
=112): those that were HIV-positive and either HBV-A mono-infected $(N=44)$, or HBV-A and -G dual infected $(N=17)$, as well as for these two groups without HIV infection $(N=42$ and $N=9$, respectively). The mean HBV-A viral load was found to be significantly lower in the group that carried all three viruses (HIV, HBV-A and HBV-G) compared with the HIV-negative group that was infected with HBV-A and HBV-G (Table 3, Student's $t$-test, twotailed, $p=0.0008)$. Comparing the HIV-positive and negative groups that were infected with HBV-A alone also showed a significant difference between their mean HBV-A viral load (Student's $t$-test, two-tailed, $p=0.04$ ).

A remarkable observation is that in the triple infected group, a viral load in the higher range $\left(>10^{5}\right.$ copies $\left./ \mathrm{ml}\right)$ was never measured in the 17 patients analysed, whereas a viral load between $10^{5}$ and $10^{9}$ copies $/ \mathrm{ml}$ was frequently seen in those infected with HBV-A alone, irrespective of their HIV status (not shown). In fact, in 12/44 (27 \%) of the HIV-positives and 19/42 (45\%) and 5/9 (56\%) of the HIV-negatives infected with HBV-A or HBV-A and -G, respectively, the viral load was between $10^{5}$ and $10^{9}$ copies $/ \mathrm{ml}$. An extremely high viral load $\left(>10^{9}\right.$ copies $\left./ \mathrm{ml}\right)$ was only observed in persons infected with $\mathrm{HBV}$-A without HBV-G, irrespective of their HIV status. Of the HIVpositives, 6/44 (14\%) and of the HIV-negative individuals $12 / 42(29 \%)$ carried a viral load $>10^{9}$ copies $/ \mathrm{ml}$.

\section{Correlation of HBV-A and HBV-G serum viral loads}

The HBV-A and HBV-G viral load in dual infected individuals $(n=40)$ is depicted in Fig. 3 . In half of the cases, viral loads for both genotypes are very similar with 20/ $40(50 \%)$ samples showing less than one $\log _{10}$ difference in viral load. The HBV-A viral load was significantly higher than the HBV-G viral load in the other half of cases. In no cases did the HBV-G viral load exceed the HBV-A viral load by more than one $\log _{10}$ difference, although there were two cases where the HBV-G viral 
Table 3 HBV-A and HBV-G viral load in HBV double- or mono-infected MSM from 1985 to 1986 with or without HIV infection

\begin{tabular}{|c|c|c|c|c|c|}
\hline \multirow[t]{2}{*}{ 1985-1986 } & \multirow[t]{2}{*}{$\mathrm{N}$} & \multirow{2}{*}{$\begin{array}{l}\text { HBV-A/G infected } \\
\text { Mean HBV-G viral load } \log _{10} \text { (range) }\end{array}$} & \multirow{2}{*}{$\begin{array}{l}\text { HBV-A/G infected } \\
\text { Mean HBV-A viral load } \log _{10} \text { (range) }\end{array}$} & \multirow[t]{2}{*}{ N } & \multirow{2}{*}{$\begin{array}{l}\text { HBV-A mono- infected } \\
\text { Mean HBV-A viral load } \log _{10} \text { (range) }\end{array}$} \\
\hline & & & & & \\
\hline HIV- negative samples & 9 & $4.06(2.96-5.74)$ & $5.32(3.73-8.76)$ & 42 & $5.66(1.30-9.46)$ \\
\hline HIV- positive samples & 17 & $2.94(0.62-4.49)$ & $3.69(2.18-4.80)$ & 44 & $4.53(2.20-9.66)$ \\
\hline$p$-value* & & 0.0063 & 0.0008 & & 0.040 \\
\hline
\end{tabular}

*Student's $t$-test, two-tailed

load was slightly higher than that of HBV-A. Both latter samples were from HIV-positive individuals.

\section{CD4+ T cell counts and HBV-DNA in HIV-positive individuals}

For 39 ACS participants without HIV infection and 96 participants with HIV infection and measurable HBV DNA, CD4+ T-cell counts at sampling date were available. Comparison of the mean CD4+ T-cell count between HIVnegative and HIV-positive individuals showed a large difference of around 300 cells/ $\mu \mathrm{l}$, which was statistically significant (Student's $t$-test, two-tailed, $p<0.0001$ ) (Fig. 4), as would be expected. There were no significant CD4+ T-cell count differences with regard to single (HBV-A) or dual infection (HBV-A + HBV-G), both in the HIV-negative or positive groups (Fig. 4). Also, there was no significant correlation between the HBV viral load in mono versus dual infected HIV-positive participants (Spearman's rank correlation coefficient $r_{\mathrm{s}}=-0.06, p=0.66$ ), suggesting that at least in this cohort-, CD4+ T-cell numbers are not related to HBV replication level. Analysing samples from the early years (1985-1986) of the ACS separately from later years (1990-1997) did not change these results.

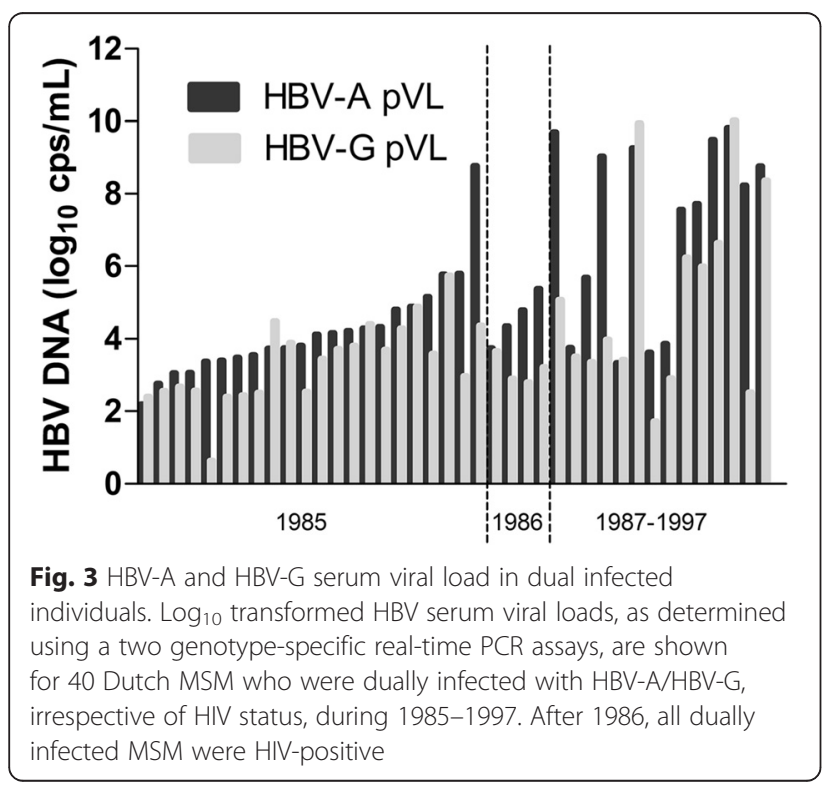

Molecular characteristics of HBV-G during 1985-1999: a G1776A mutation in a subset of patients

For 29 samples from 45 HBV-G infected individuals, sufficient quantities of the blood serum sample were available to amplify a $268 \mathrm{bp}$ fragment spanning the precore and core region of the genome for sequence analysis. The sequences were investigated for the presence of the characteristic features of present-day HBV-G, one or two stop codons in the precore region and a $36 \mathrm{bp}$ insertion into the core gene. All sequences from 1985 till 1997 contained these features, suggesting that HBV-G from 1985 was genetically similar to the later isolates. The only sequence variation observed was a single G1776A mutation that was present in $15 \mathrm{HBV}$-isolates from 1985 to 1997 (Fig. 5). Six HBV-G isolates carrying this mutation were from HIV-negative MSM and $9 \mathrm{HBV}-\mathrm{G}$ isolates were from HIV-positive MSM.

\section{Discussion}

In this study, we have retrospectively analysed the prevalence of HBV genotype G in MSM from the Amsterdam area in the early years of the HIV epidemic and found it to be widely present from 1985 onwards in HBV-seropositive MSM. The early HBV-G isolates were genotypically highly similar to later isolates and contained the distinctive characteristics of HBV-G, being two stop codons in the precore region precluding $\mathrm{HBeAg}$ expression and a $36 \mathrm{bp}$ insertion in the core gene. In 1985 and 1986, the prevalence of HBV-G was similar between HIV-positive and HIV-negative MSM, suggesting that risk group and thus risk behaviour is important for acquisition of the virus. Being HIV- infected apparently does not serve as an additional risk factor. After 1986 there was a sharp decrease in the HBV DNA positivity that was already observed as a decline in seroprevalence during patient selection for the present study. The steep decline in HBV prevalence has been observed for the ACS in general. Van Houdt et al. reported that the overall incidence of anti-HBc seroconversion was highest in 1985-1986, declined afterwards, and remained stable thereafter up to 2003, when routine vaccination was started for this risk group [29]. HBV-DNA positivity in HIV-negative MSM disappeared after 1987, although two HIV-negative samples from that period (dating to 1996 and 1999, respectively) were selected for this study because of positive HBV serology. The decline in 


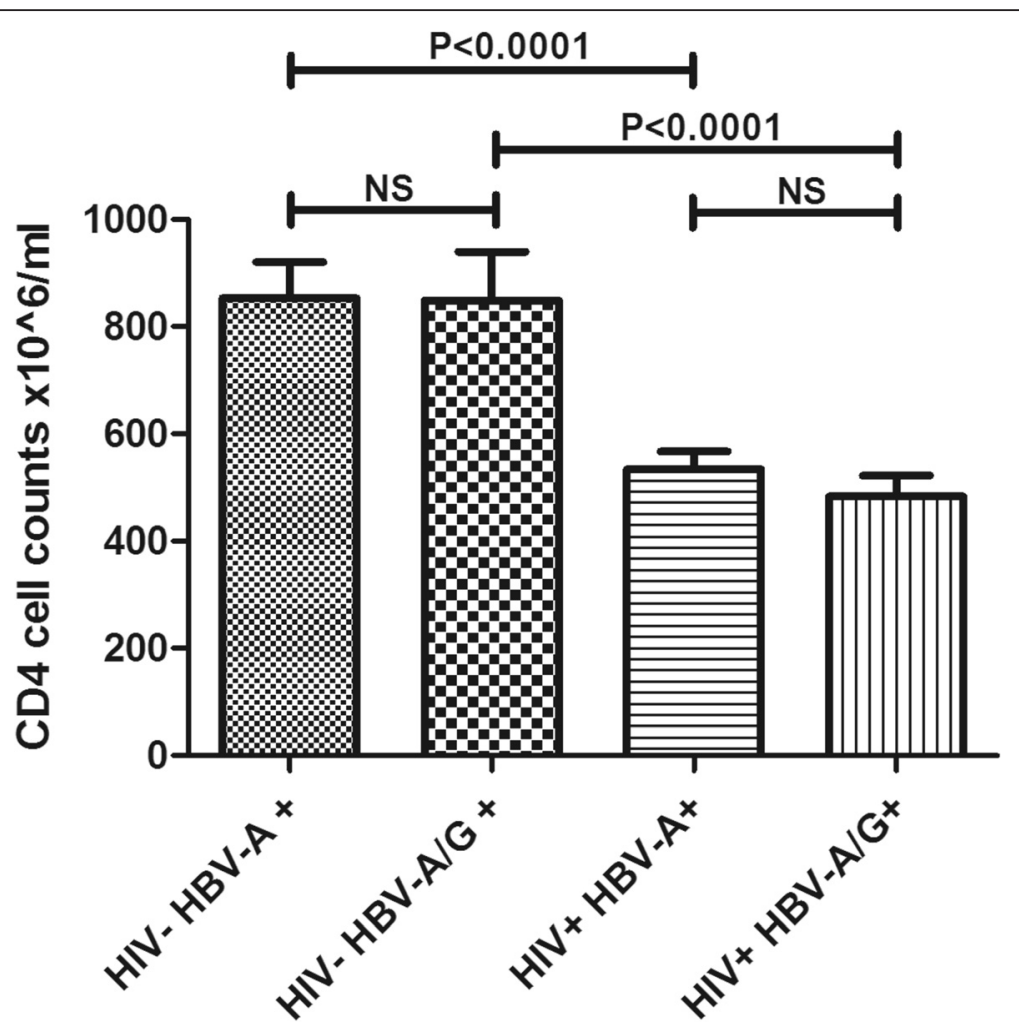

Fig. 4 Mean CD4+ T-cell counts in ACS participants with or without HIV infection and measurable HBV-A or HBV-A/HBV-G DNA. The mean CD4+ T-cell counts are shown for HIV-negative/HBV-A DNA positive MSM ( $N=30$, mean $853 \pm 68$ cells/ $\mu \mathrm{l})$, HIV-negative/HBV-A + HBV-G DNA positive

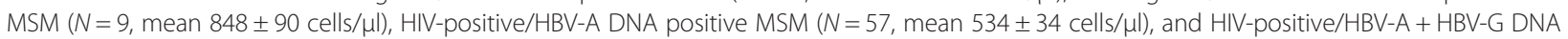
positive MSM ( $N=28$, mean $483 \pm 39$ cells/ $\mu$ l), respectively. Statistical significance is indicated by p-values (Student's $t$-test, two-tailed, NS = not significant). CD4+ T-cell ranges are 290-1710 cells/ $\mu$ l for HIV-negative MSM and 90-1310 cells/ $\mu$ for HIV-positive MSM

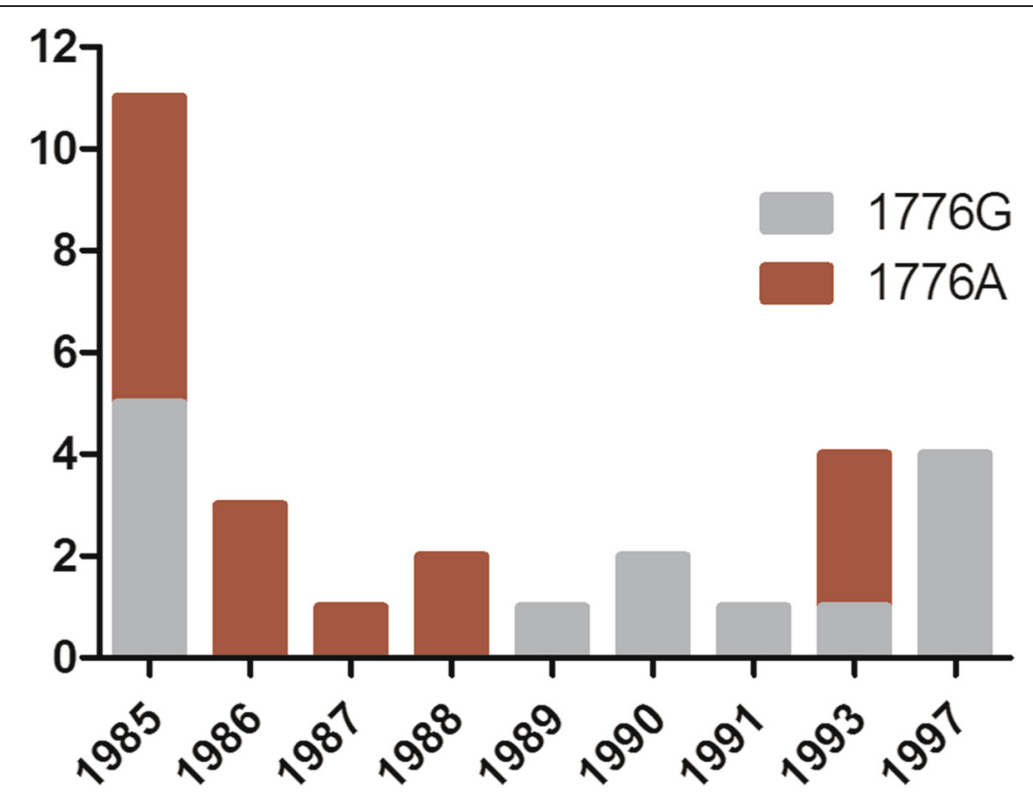

Fig. 5 Numbers of HBV-G isolates with or without the G1776A mutation during 1985-1997. A nested PCR amplifying nt 1751-2034 of the HBV genome was sequenced for 29 HBV-G isolates to investigate the evolution of this region during 1985-1997. A G1776A mutation was detected in 15 of the isolates dating to $1985-1993$ 
HBV positivity possibly relates to decreased risk behaviour as anti-HBV vaccination was negligible at that time. It is possible that the age of the samples could have influenced our study, as some samples have been stored for almost 30 years. However, we believe that sample age did not influence our results, firstly because most samples that were HBV DNA positive were from 1985, and secondly because the real-time PCR amplifies very short DNA fragments, and in general only amplification of longer fragments is affected by DNA degradation.

HBV-G sequence variation in the 1985-1997 period was extremely low. Two fragments of in total $1029 \mathrm{bp}$ of the $3.2 \mathrm{~kb}$ genome were sequenced for 29 Dutch HBV-G isolates and only a single nucleotide substitution, G1776A, was found in $50 \%$ of the isolates from 1985 to 1993 in both HIV-negative and positive individuals. This specific mutation is often seen in the chronic phase of other HBV genotypes, which have been correlated to liver pathology [17, 33]; it has not yet been reported in HBV-G sequences obtained from other geographic regions than the Netherlands. The G1776A mutation contributes to the "late stage" genotype of $\mathrm{HBV}-\mathrm{G}$ that also includes the 2 precore stop codons and the T1753C/A1762T/G1764A/ G1896A core promoter mutations that are fixed in HBV$\mathrm{G}$ genomes. HBV-G infection has been associated with liver fibrosis [10, 22], although others found no such relation [34]. In mice, dual, but not single infection with HBV-A and HBV-G or HBV-H and HBV-G leads to increased liver fibrosis $[35,36]$. It is possible that the G1776A mutation occurred de novo in different patients, but it seems more likely that these two strains were circulating in Amsterdam at least since 1985. An HBV-G strain from an HIV-positive patient presenting with acute HBVA and -G infection in Amsterdam in 2003 also did carry this mutation [4], suggesting that the variant strain did not disappear from the Amsterdam region after 1993.

The low sequence variation seen in HBV-G during 19851997 is not unique for this specific genotype, as very little nucleotide differences were reported for a 672 nt pre-S2 and $\mathrm{S}$ region fragment of HBV-A in the same cohort from 1985 till 2002 [29]. A recent phylogenetic analysis indeed proposed a very low substitution rate for HBV [27].

Five apparent HBV-G mono-infections were detected in MSM samples from 1985, 1991 and 1997. No other genotype commonly associated with HBV-G infection (e.g. HBV-A, $-\mathrm{C},-\mathrm{D},-\mathrm{F}$, or $-\mathrm{H}$ ) could be amplified from these samples. All five samples were HBsAg positive, which is not incompatible with HBV-G mono-infection. HBsAg expression can be decreased or delayed in mono-G infections, but it has frequently been reported to occur [14-16]. HBV-G apparently does not express HBeAg [17], and therefore the samples were tested for the presence of the HBV "e" antigen. Indeed, four samples were HBeAg-negative, which could be an indication, but not definite proof, of mono- infection. In HBeAg-positive infection, expression leads to HBeAb seroconversion and elimination of hepatocytes expressing $\mathrm{HBeAg}$, and thus to disappearance of detectable HBeAg (see: [37]). Acute HIV-1 infection can lead to a loss of HBeAg, but none of our five patients were HIV seroconverters at the time of sampling, and two individuals were actually HIV-negative. Control dual infected samples from 1985 and 1991 also showed no measurable HBeAg levels, suggesting that sample age and/or storage condition could have interfered with performance of the assay. Summarizing, only one sample from 1997 could likely represent an HBV-G mono-infection, as HBeAg expression in the other sample from 1997 suggests the presence of a helper genotype. However, repeated attempts to amplify this virus failed, even when using patient samples from an earlier or later time point.

A cross-sectional analysis of the viral load of HBV-A and HBV-G in MSM from the early years of the HIV epidemic in Amsterdam revealed that in 1985-1986, being HIV-infected resulted in a significantly lower viral load of both HBV-A and HBV-G compared with HIV-uninfected MSM. It has been reported that acute HIV-1 infection results in decreased HBV DNA levels, suggesting that the immune activation induced by HIV is beneficial for controlling HBV replication [38, 39]. In some cases, the HBV DNA viral load remained low for as long as two years after acute HIV-1 infection [38]. In the ACS, MSM enrolled in 1985-1986 were not likely to be in the AIDS stage of HIV infection as they had to be asymptomatic to be eligible for inclusion. This may provide an explanation for the significantly decreased HBV viral load in the HIV-positive group. In this cohort, absolute CD4+ T-cell counts were not related to HBV viral load, neither in mono-infected nor in dual HBV-infected individuals. This suggests that CD4+ T-cells are not significantly involved in suppression of HBV replication. In a large multinational study of HBV and HIV-infected individuals, low CD4+ T-cell counts were related to high HBV DNA loads [40]. However, the relation was best noticeable when $\mathrm{CD} 4+\mathrm{T}$-cell counts declined to below 50 cells/ $\mu \mathrm{l}$, which is much lower than the CD4+ T-cell counts in our patient selection. In addition, in MSM with chronic HBV-infection an association between HIV infection and higher HBV levels has been reported [41]. As the chronicity of HBV infection has not been determined in our cohort, e.g. liver enzymes and liver pathology were not investigated, this discrepant finding might be related to the heterogeneous composition of our selection with regard to the unidentified stages of both HBV and HIV infections.

\section{Conclusions}

An analysis of the prevalence and characteristics of HBV genotype G in 1984-1999 in a cohort of MSM in the Netherlands was performed in the present study. The 
results show that HBV-G was already widely present among Dutch MSM in 1985. In this cohort, HIV status was not associated with HBV-G infection, but the HBV viral load of both genotype A and $\mathrm{G}$ in mono-A or dual A/G infected MSM was significantly lower in HIVinfected men, confirming the beneficial effect of HIV infection in controlling HBV replication. HBV-G isolates from 1985 contain both genetic features reported for this genotype: stop codons in the precore region and a 36 bp insertion in the core gene. HBV-G sequence variation was extremely limited to a G1776A mutation that was seen throughout the study period in approximately half of the patient isolates, suggesting the circulation of two slightly divergent HBV-G lineages among MSM in the Netherlands.

\section{Additional file}

Additional file 1: Table S1. Contains the sequences of the PCR-primers used in the study. (XLS $39 \mathrm{~kb}$ )

\section{Abbreviations}

HBV, hepatitis B virus; HIV, human immunodeficiency virus; IUD, intravenous drug use; MSM, men who have sex with men; nt, nucleotide; bp, base pair

\section{Acknowledgements}

The authors thank dr. Robin van Houdt (GGD Amsterdam, Amsterdam, the Netherlands) for sharing data on the HBsAg and HBCAb assays and dr. Janke Schinkel (Laboratory of Clinical Virology, Dept. of Medical Microbiology, AMC, Amsterdam, the Netherlands) for performing the HBeAg assay.

The Amsterdam Cohort Studies on HIV infection and AIDS, a collaboration between the Public Health Service of Amsterdam, the Academic Medical Center of the University of Amsterdam, Sanquin Blood Supply Foundation, Medical Center Jan van Goyen and the HIV Focus Center of the DC-Clinics, are part of the Netherlands HIV Monitoring Foundation and financially supported by the Center for Infectious Disease Control of the Netherlands National Institute for Public Health and the Environment.

\section{Funding}

There was no specific funding for this study.

\section{Authors' contributions}

MC designed and analysed the experiments, FZ performed the experiments, $\mathrm{SMB}$ performed the $\mathrm{HBsAg}$ and $\mathrm{HBCAb}$ assays, MB performed the database selections, BB edited the manuscript, and ACvdK analysed the data and drafted the manuscript. All authors have read and approved the final version of the manuscript.

\section{Competing interests}

The authors declare that they have no competing interests.

\section{Consent for publication}

Not applicable.

\section{Ethics approval and consent to participate}

The ACS, a collaboration between the Public Health Service of Amsterdam, the Academic Medical Center (AMC) of the University of Amsterdam, and the Sanquin Blood Supply Foundation, are part of the Netherlands HIV Monitoring Foundation and financially supported by the Netherlands National Institute for Public Health and the Environment (RIVM). Since 1984 cohorts of MSM and IDUs are followed to study the epidemiology and pathogenesis of HIV/AIDS and other blood borne and sexually transmitted infections and the effects of interventions. Of each participant blood is frequently drawn for virological and immunological tests and serum and leukocytes were stored. The ACS have been conducted in accordance with the ethical principles set out in the declaration of Helsinki, and ACS participation is voluntary: written informed consent (approved by the AMC Medical Ethics Committee in 2007 for the MSM cohort and in 2009 for the IDU cohort) was obtained for every participant.

\section{Author details}

'Laboratory of Experimental Virology, Department of Medical Microbiology, Center for Infection and Immunity Amsterdam (CINIMA), Academic Medical Center of the University of Amsterdam, Meibergdreef 15, 1105 AZ Amsterdam, The Netherlands. 'Public Health Laboratory, GGD Amsterdam, Cluster Infectious Diseases, Nieuwe Achtergracht 100, Amsterdam 1018 WT, The Netherlands.

Received: 5 January 2016 Accepted: 27 May 2016

Published online: 10 June 2016

\section{References}

1. Croagh CM, Desmond PV, Bell SJ. Genotypes and viral variants in chronic hepatitis B: A review of epidemiology and clinical relevance. World J Hepatol. 2015:7:289-303.

2. Hahne SJ, Veldhuijzen IK, Wiessing L, Lim TA, Salminen M, Laar M. Infection with hepatitis $B$ and $C$ virus in Europe: a systematic review of prevalence and cost-effectiveness of screening. BMC Infect Dis. 2013;13:181.

3. van Houdt R, Bruisten SM, Koediijk FD, Dukers NH, Op de Coul EL, Mostert MC, Niesters HG, Richardus JH, de Man RA, van Doornum GJ, van den Hoek JA, Coutinho RA, van de Laar MJ, Boot HJ. Molecular epidemiology of acute hepatitis B in the Netherlands in 2004: nationwide survey. J Med Virol. 2007; 79:895-901.

4. van der Kuyl AC, Zorgdrager F, Hogema B, Bakker M, Jurriaans S, Back NK, Berkhout B, Zaaijer HL, Cornelissen M. High prevalence of hepatitis B virus dual infection with genotypes A and G in HIV-1 infected men in Amsterdam, the Netherlands, during 2000-2011. BMC Infect Dis. 2013;13:540.

5. Vieth S, Manegold C, Drosten C, Nippraschk T, Gunther S. Sequence and phylogenetic analysis of hepatitis B virus genotype $\mathrm{G}$ isolated in Germany. Virus Genes. 2002;24:153-6.

6. Perez-Olmeda M, Nunez M, Garcia-Samaniego J, Rios P, Gonzalez-Lahoz J, Soriano V. Distribution of hepatitis B virus genotypes in HIV-infected patients with chronic hepatitis B: therapeutic implications. AIDS Res Hum Retroviruses. 2003:19:657-9.

7. Shibayama T, Masuda G, Ajisawa A, Hiruma K, Tsuda F, Nishizawa T, Takahashi M, Okamoto H. Characterization of seven genotypes ( $A$ to $E, G$ and $H$ ) of hepatitis $B$ virus recovered from Japanese patients infected with human immunodeficiency virus type 1. J Med Virol. 2005;76:24-32.

8. Sanchez LV, Tanaka Y, Maldonado M, Mizokami M, Panduro A. Difference of hepatitis $B$ virus genotype distribution in two groups of mexican patients with different risk factors. High prevalence of genotype $\mathrm{H}$ and $\mathrm{G}$. Intervirology. 2007:50:9-15

9. Osiowy C, Gordon D, Borlang J, Giles E, Villeneuve JP. Hepatitis B virus genotype $\mathrm{G}$ epidemiology and co-infection with genotype A in Canada. J Gen Virol. 2008:89:3009-15.

10. Dao DY, Balko J, Attar N, Neak E, Yuan HJ, Lee WM, Jain MK. Hepatitis B virus genotype $\mathrm{G}$ : prevalence and impact in patients co-infected with human immunodeficiency virus. J Med Virol. 2011;83:1551-8.

11. Araujo NM, Araujo OC, Silva EM, Villela-Nogueira CA, Nabuco LC, Parana R, Bessone F, Gomes SA, Trepo C, Kay A. Identification of novel recombinants of hepatitis $B$ virus genotypes $F$ and $G$ in human immunodeficiency viruspositive patients from Argentina and Brazil. J Gen Virol. 2013;94:150-8.

12. Coffin CS, Osiowy C, Myers RP, Gill MJ. Virology and clinical sequelae of long-term antiviral therapy in a North American cohort of hepatitis B virus (HBV)/human immunodeficiency virus type 1 (HIV-1) co-infected patients. J Clin Virol. 2013;57:103-8.

13. Escobedo-Melendez G, Panduro A, Fierro NA, Roman S. High prevalence of occult hepatitis $B$ virus genotype $H$ infection among children with clinical hepatitis in west Mexico. Mem Inst Oswaldo Cruz. 2014;109:728-37.

14. Zaaijer HL, Boot HJ, van Swieten P, Koppelman MH, Cuypers HT. HBsAgnegative mono-infection with hepatitis B virus genotype G. J Viral Hepat. 2011;18:815-9.

15. Chudy M, Schmidt M, Czudai V, Scheiblauer H, Nick S, Mosebach M, Hourfar MK, Seifried E, Roth WK, Grunelt E, Nubling CM. Hepatitis B virus genotype $\mathrm{G}$ monoinfection and its transmission by blood components. Hepatology. 2006:44:99-107. 
16. Sayan M, Dogan C. Hepatitis B virus genotype $\mathrm{G}$ infection in a Turkish patient undergoing hemodialysis therapy. Hepat Mon. 2012;12:118-21.

17. Li K, Zoulim F, Pichoud C, Kwei K, Villet S, Wands J, Li J, Tong S. Critical role of the 36-nucleotide insertion in hepatitis B virus genotype $\mathrm{G}$ in core protein expression, genome replication, and virion secretion. J Virol. 2007;81:9202-15.

18. Cotelesage JJ, Osiowy C, Lawrence C, DeVarennes SL, Teow S, Beniac DR, Booth TF. Hepatitis B Virus Genotype G forms core-like particles with unique structural properties. J Viral Hepat. 2011;18:443-8.

19. Tran A, Kremsdorf D, Capel F, Housset C, Dauguet C, Petit MA, Brechot C. Emergence of and takeover by hepatitis $B$ virus $(\mathrm{HBV}$ ) with rearrangements in the pre-S/S and pre-C/C genes during chronic HBV infection. J Virol. 1991; 65:3566-74.

20. Kato H, Orito E, Gish RG, Sugauchi F, Suzuki S, Ueda R, Miyakawa Y, Mizokami $M$. Characteristics of hepatitis $B$ virus isolates of genotype $G$ and their phylogenetic differences from the other six genotypes (A through F). J Virol. 2002;76:6131-7.

21. Kato H, Orito E, Gish RG, Bzowej N, Newsom M, Sugauchi F, Suzuki S, Ueda R, Miyakawa $Y$, Mizokami M. Hepatitis B e antigen in sera from individuals infected with hepatitis B virus of genotype G. Hepatology. 2002;35:922-9.

22. Lacombe K, Massari V, Girard PM, Serfaty L, Gozlan J, Pialoux G, Mialhes P, Molina JM, Lascoux-Combe C, Wendum D, Carrat F, Zoulim F. Major role of hepatitis $B$ genotypes in liver fibrosis during coinfection with HIV. AIDS. 2006;20:419-27.

23. Kato H, Gish RG, Bzowej N, Newsom M, Sugauchi F, Tanaka Y, Kato T, Orito E, Usuda S, Ueda R, Miyakawa Y, Mizokami M. Eight genotypes (A-H) of hepatitis $B$ virus infecting patients from San Francisco and their demographic, clinical, and virological characteristics. J Med Virol. 2004;73:516-21.

24. Erhardt A, Gobel T, Ludwig A, Lau GK, Marcellin P, van Bommel F, HeinzelPleines $U$, Adams $\mathrm{O}$, Haussinger D. Response to antiviral treatment in patients infected with hepatitis B virus genotypes E-H. J Med Virol. 2009;81: $1716-20$.

25. Beggel B, Neumann-Fraune M, Doring M, Lawyer G, Kaiser R, Verheyen J, Lengauer T. Genotyping hepatitis B virus dual infections using populationbased sequence data. J Gen Virol. 2012;93:1899-907.

26. Stuyver L, De Gendt S, Van Geyt C, Zoulim F, Fried M, Schinazi RF, Rossau R. A new genotype of hepatitis B virus: complete genome and phylogenetic relatedness. J Gen Virol. 2000;81:67-74.

27. Paraskevis D, Angelis K, Magiorkinis G, Kostaki E, Ho SY, Hatzakis A. Dating the origin of hepatitis $B$ virus reveals higher substitution rate and adaptation on the branch leading to F/H genotypes. Mol Phylogenet Evol. 2015;93:44-54.

28. Coutinho RA, Krone WJ, Smit L, Albrecht-van Lent P, van der Noordaa J, Schaesberg W, Goudsmit J. Introduction of lymphadenopathy associated virus or human T lymphotropic virus (LAV/HTLV-III) into the male homosexual community in Amsterdam. Genitourin Med. 1986;62:38-43.

29. van Houdt R, Bruisten SM, Geskus RB, Bakker M, Wolthers KC, Prins M, Coutinho RA. Ongoing transmission of a single hepatitis $B$ virus strain among men having sex with men in Amsterdam. J Viral Hepat. 2010;17:108-14.

30. CodonCode Corporation [www.codoncode.com/aligner/]

31. NCBI nucleotide database [www.ncbi.n/m.nih.gov/nucleotide/]

32. BioEdit Sequence Alignment Editor version 7.0.9 [www.mbio.ncsu.edu/ BioEdit/bioedit.html]

33. Zhang D, Ma S, Zhang X, Zhao H, Ding H, Zeng C. Prevalent HBV point mutations and mutation combinations at $B C P / p r e C$ region and their association with liver disease progression. BMC Infect Dis. 2010;10:271.

34. Calin R, Guiguet M, Desire N, Imbert-Bismut F, Munteanu M, Poynard T, Valantin MA, Stitou H, Katlama C, Thibault V. Role of genotype G hepatitis B virus mixed infection on the progression of hepatic fibrosis in HIV positive patients over 5 years of follow-up. J Clin Virol. 2013;58:408-14.

35. Sugiyama M, Tanaka Y, Sakamoto T, Maruyama I, Shimada T, Takahashi S, Shirai T, Kato H, Nagao M, Miyakawa Y, Mizokami M. Early dynamics of hepatitis B virus in chimeric mice carrying human hepatocytes monoinfected or coinfected with genotype G. Hepatology. 2007:45:929-37.

36. Tanaka Y, Sanchez LV, Sugiyama M, Sakamoto T, Kurbanov F, Tatematsu K, Roman S, Takahashi S, Shirai T, Panduro A, Mizokami M. Characteristics of hepatitis $B$ virus genotype $\mathrm{G}$ coinfected with genotype $\mathrm{H}$ in chimeric mice carrying human hepatocytes. Virology. 2008;376:408-15.

37. Sakamoto T, Tanaka Y, Watanabe T, lijima S, Kani S, Sugiyama M, Murakami S, Matsuura K, Kusakabe A, Shinkai N, Sugauchi F, Mizokami M. Mechanism of the dependence of hepatitis B virus genotype $\mathrm{G}$ on co-infection with other genotypes for viral replication. J Viral Hepat. 2013;20:e27-36.
38. Thio CL, Netski DM, Myung J, Seaberg EC, Thomas DL. Changes in hepatitis $B$ virus DNA levels with acute HIV infection. Clin Infect Dis. 2004:38:1024-9.

39. Jiao Y, Li N, Chen X, Zhang T, Li H, Li W, Huang X, Liu Z, Zhang Y, Wu H. Acute HIV infection is beneficial for controlling chronic hepatitis B. Clin Infect Dis. 2015;60:128-34.

40. Thio CL, Smeaton L, Saulynas M, Hwang H, Saravanan S, Kulkarni S, Hakim J, Nyirenda M, Iqbal HS, Lalloo UG, Mehta AS, Hollabaugh K, Campbell TB, Lockman S, Currier JS. Characterization of HIV-HBV coinfection in a multinational HIV-infected cohort. AIDS. 2013;27:191-201.

41. Colin JF, Cazals-Hatem D, Loriot MA, Martinot-Peignoux M, Pham BN, Auperin A, Degott C, Benhamou JP, Erlinger S, Valla D, Marcellin P. Influence of human immunodeficiency virus infection on chronic hepatitis $B$ in homosexual men. Hepatology. 1999;29:1306-10.

\section{Submit your next manuscript to BioMed Central and we will help you at every step:}

- We accept pre-submission inquiries

- Our selector tool helps you to find the most relevant journal

- We provide round the clock customer support

- Convenient online submission

- Thorough peer review

- Inclusion in PubMed and all major indexing services

- Maximum visibility for your research

Submit your manuscript at www.biomedcentral.com/submit
) Biomed Central 